Alcohols form an exception, having a comparatively high specific heat; they gave the differences 9.7 and 8.5 respectively. Isomeric substances of similar composition have the same molecular heat, while those of unlike composition have ?a different. In the tables which give carbon and hydrogen differences there are exceptions along with regularity. For a right development of the theory Herr von Reis feels that more extended observation is necessary.

THE idea of qualitative analysis of substances by microscopical examination of crystalline forms is worked out to some extent by Herr Lehmann (Wied. Ann., No. 7). A shallow watch-glass is substitnted for the cover glass, and serves for turning over in various ways the crystals which form in the inclosed solution. The domain of regular forms is avoided as unsuitable, and only irregular forms observed-the so-called growth-torms, crystal skeletons, trichites, \&c., produced by acceleration of crystallisation, viscosity, and $\mathrm{s}^{\prime}$ on. For details of Herr Lehmann's method and apparatus we must refer to his paper.

HERR SchulLer has lately described to the Hungarian Academy of Sciences (Wied. Ann., No. 7) a mercury air-pump which works automatically, and in which all greased glass combinations are dispensed with, the hermetic closure being effected with only glass and mercury. The evacuating power of the apparatus was not exactly measured ; there are proofs that it is high.

MR. J. MILnE has written a careful account of the vertica and horizontal motions accompanying the earthquake of March 8 , $88 \mathrm{I}$, in Japan. This is believed to be the first earthquake in which a complete continuous. record of both components of the motion has been obtained for a period exceeding twenty. five seconds. The actual maximum displacement appeared to be about I'33 millims., recurring at the rate of about seven vibra. tions in five seconds. From the phenomena of this shock, ard from some experiments on artificial earthquakes produced by letting an iron ball weighing about one ton fall from a height of about thirty-five feet, Mr. Milne argues that the waves that are felt are transverse to the line of propagation of the shock.

\section{BIOLOGICAI NOTES}

Relations BeTWEen THE CRANIUM AND THE REST OF THE SKELETON.-These relations form the subject of a paper by M. Manouvrier, read at the last meeting of the French Association. The following are the author's conclusions:- $-\mathbf{r}$. The weight of the cranium varies, in a general way, with the weight of the skeleton, but nat proportionally, like the weight of the brain. 2. The weight of the skeleton, less the cranium, in a given race, varies nearly in proportion to the weight of the femur. 3. The weight of the cranium is greater relatively to that of the femur, the lighter the latter is. 4. The weight of the cranium is much more considerable relatively to that of the femur in woman than in man. 5. This sexual difference is so pronounced that it constitutes one of the best secondary sexual charactcrs. About 82 women in 100 have the cranium heavier than the two femurs, while 82 men in Ioo have it lighter. 6. The lower jaw is heavier relatively to the crapium in the anthro. poids than in man, is inferior than in civilised races, in man than in woman, and in the adult than in the cliild. 7. The weight of the cranium is smaller relatively to that of the lower jaw, the heavier the latter is, \&c.

The Colour Changes of Axolotl.-Prof. Semper has lately examined axolotl with regard to the influence of light on its colour (Wiirrburg Phys. med. Ges.). When young axolotl are reared in darkness they become quite dark; nearly as dark in red light; in yellow, on the other hand, pretty bright; and brightest in bright daylight. The difference is connected not only with the chromatic function found in various degrees in all amphibia, but on pronounced formation of a peculiar diffuse yellowish green colouring matter, increase of white, and diminution of dark chromatophores. Further, when axolotl are exposed to daylight in white dishes covered with white paper, much less dark pigment forms in them than when they are kept in white dishes without a paper cover (other things equal); though in the latter case they are apparently exposed to the most intense light; these darker axolotl are, however, still mueh brighter than those reared in red light or in darkness. Since (as experiment showed) the white covering paper let through much light, but very little of the chemical rays, it appears that chemical rays play no part in the formation of pigment. Put the causes of the whitening in bright daylight and the dark ening in absence of light remain unknown as before.

Siredon Lichenordes.-Mr. W. E. Carlin publishes in the June number of the Proceedings of the United States National Museum some very interesting details about this remarkable form. Its chief habitat is a body of water some two and a half miles in circumference called Como Lake. This has no known outlet, but is fed by a perennial stream of pure spring "water. The lake is shallow, and its water very strongly impreg. nated with an alkali; it is very disagreeable to the taste. The Siredon never enter the fre:hwater stream; they abound in the alkaline waters of the lake in immense numbers. When about one hundred and fifty were placed in fresh water they seemed to suffer no inconvenience, but it had a remarkable effect in hastening their metamorphosis into the Amblystoma form. Of an equal number kept in fresh water and in the lake water, quite a change occurred with the former after twenty-four hours, while the latter showed no change after several days of captivity. Those that were kept well fed in jars usually began to show a slight change in from two to three weeks, and all of them completed the change into the Amblystoma inside of six weeks, while in some kept, but not specially fed, there were but three changes in three months. Specimens kept in captivity became quite tame, soon learning to know that tapping the jar in which they were, meant a fly, and, rising to the surface, would snap at whatever they saw first, pencil or fly.

Fish Mortality in the Gulf of Mexico.-We glean a few more particulars as to this strange mortality from the June Proceedings of the United States National Museum. The fishing interest of Key West is an important one, supplying thousands with the means of subsistence. The fishermen state that a volcanic spring exists, the waters from which are of a high tempera. ture. The polluted waters are of a red brick colour; their influence is seen for a distance of 200 miles. A scant supply of sea water from the Gulf of Mexico sent to Washington was examined by Mr. F. M. Endlich of the Smithsonian Institution. That in which the fish died (A) contained a large quantity of algre and infusoria, and the pure water (B) had none. They gave the following analysis:-

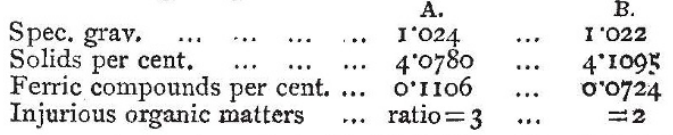

Even on spectros copic analysis Mr. Endlich could not find in A any mineral constituent which could noxiously affect the fish, and he thinks that death must be caused by parasitic alga, wbile Surgeon Glazier agrees with the prevalent opinion that the catastrophe is due to the salt vater being impregnated with gases discharged from volcanic or geyser-like springs. During November last the waters of Tampa, Sarasota, and Charlotte Harbour were covered with thousands of dead fish, and the stench was qui ${ }^{2}$ overpowering.

THE BLOOD OF INSECTS.-Operating with the larva of Oryctes nasicornis, M. Fredericq has observed (Bull. Belg. Acad.) that the blood of the animal, drawn off in a small glass cannula, is a colourless liquid, but on exposure to the air presently takes a decided brown colour, and coagulates. The coloration he regards as a purely cadaveric phenomenon. The substance which becomes brown is probably formed in the moment of coagulation, and does not serve in the body as a vehicle between the external air and the tissues, like hamoglobin in Vertebrates and many Annelids, hronocyanin in Crustaceans, \&c. When the larva is ket $t$ a quarter of an hour in hot water $\left(50^{\circ}\right.$ to $\left.55^{\circ}\right)$, the bleord extracted does not coagulate or become brown. Once the substance which browns is produced, even a boiling temperature does not prevent its browning. The broun substance once formed is very stable, not being decomposed either by acids or alkalies, and not made colourless by being submitted to vacuum or kept in a closed vessel. The existence of an intermediary in insects corresponding to hæmoglobin $M$. Fredericq thinks wery problematical in view of the anatomical system, letting air penetrate into the heart of the tissues.

NEw PYCNOGONIDA.-The result of the examination of the collection of Pycnogons made during the cruise of the U.S. steamer Blake by F.dmund B. Wilson, has just been published as No. 12, vol. viii. of the Harvard College Museum Bulletin. This collection was found to possess features of considerable interest, and though the species in it were few, some of them 
were of remarkable size, quite colossal in comparison with shallow water or littoral forms. Of the three species of Colossendeis, two of which are described as new, the smallest has a span of $14 \mathrm{~cm}$. between the tips of its outstretched legs, while the largest has an extent four times as great. A new genus (Scæorhynchus) has been established for a species with a span of I9 $\mathrm{cm}$., a gigantic size as compared with the dimensions of its nearest allies. The most abundant species of Nymphon is the largest of that extensive genus, and one species of a new genus (Pallenopsis) is more than twice as large as any of the species of allied genera, such as Pallene, which are known only from the littoral zone. It is further interesting to note that in a number of forms the visual organs (ocelli) are either rudimentary and destitute of pigment, or are entirely absent. In Pallenopsis, however, the ocelli are relatively of unusually great size. The species of Scæorhynchus and Colossendeis show clearly from anatomical evidence the complete independence of the accessory legs and the first pair of ambulatory legs, as had been already proved by Dohrn from embryological data. In all cases the palpi and accessory legs are supplied with nerves from the same ganglion, and this latter shows in the adult no indication of being composed of two coalesced ganglia. But Dohrn states that there are in the larvæ of Achelia two ganglia. This question is of great interest, having a direct bearing on the affinities of these Pycnogons with the Arachnids. Mr. Wilson describes ten species, of which one half are given as new, and with figures.

New Zealand Desmids, -As a contribution to our knowledge of the pretty green unicellular algæ known as Desmids, which are to be met with in New Zealand, Mr. Maskell's paper in the recently-published rolume of the Transactions of the New Zealand Institute is most welcome. It would seem to render more than probable the idea that these minute algæ are to a large extent cosmopolitan. The author is evidently under great disadvantage as to identifying the species he meets with, but this is to a great extent done away with by his fairly careful descriptions and accurate (as to outline) figures. $\mathrm{He}$ enumerates between sixty and sixty-five species, some of which are very noteworthy and fine additions to the list of Desmids; thus Aptogonum undulatum is a highly interesting new species. Triploceras bidentatum is not only a very distinct, but also a very noble, new species, and equally distinct as a species is his Closterium selencum. Doubtless a more prolonged search in fresh localities will enable the author to add many old and new species to the list. He may feel sure that his further researches will be looked for with interest by those working at the freshwater algæ in Europe.

Protoplasm Stained whilst Living.-Mr. L. F. Henneguy publishes the result of some experiments made on living infusoria, in which he confirms the observations of Brandt, made in 1879 , that an aqueous solution of aniline brown, known in commerce as Bismarck brown, will give an intense brownish. yellow colour to the protoplasm of the infusoria without in any way interfering with their enjoyment of life. The coloration first appears in the vacuoles of the protoplasm, then this latter is itself stained, the nucleus being most generally not at first coloured, and so being made more conspicuous. Experiments made on vegetable protoplasm seemed to exhibit the same result.

\section{LARGE TELESCOPES 1}

THE small amount of work accomplished with large telescopes has often been the subject of unfavourable comment. Thi criticism applies with especial force in America, where there are nearly a dozen telescopes having an aperture of a foot or over, besides two of the largest size now in course of construc tion, and two of twenty-six and twenty-four inches aperture which are unmounted and have been for several years perfectly useless. Among so many it seems as if one might be spared for a trial of the following plan, which, if successful, would produce at a small expense far more work than could be obtain $d$ with a mounting of the usual form.

Suppose that the telescope is placed horizontally at right angles to the meridian, and that a plane reflector inclined to its axis by $45^{\circ}$ is placed in front of it. This reflector may revolve around an axis coimciding with that of the telescope. Such a mounting has been used in transit instruments, and gives mauch I By Edward C. Pickering, communicated by the author. satisfaction in the meridian photometer of the Harvard College Observatory. The principal difficulty with a large instrument would lie in the flexure of the reflector. This difficulty has how. ever been overcome in a great measure in reflecting telescopes by various ingenious devices. In the present case, since the refiector rotates only around one axis instead of two, the problem is much simplified. A slight motion at right angles of perhaps $5^{\circ}$ would be a great convenience, as will be shown below, and would probably be insufficient to materially affect the flexure. It may be said that it is more difficult to make a plane surface than one that is curved. But the principal effect of a slight curvature would be to change the focus of the telescope, the aberration being much less than the effect of the varying flexure. Let us admit, however, that the best definition cannot be obtained, in considering the purposes to which such an instrument could be applied without disadvantage.

Many advantages will be apparent on comparing such a mounting with an equatorial. Great steadiness would be secured, since the mirror would be the only portion moved, and this would be placed directly upon a low pier. Instead of a large and expensive dome which is moved with difficulty, the mirror would be protected by a small shed, of which the roof could be easily removed. It would therefore be opened and ready for use in a very short time, and would quickly take the temperature of the surrounding air. The object-glass would be mounted directly upon a second pier, and, as it would not be moved, would be in very little danger of accident. The tube could be made of tin or other inexpensixe material, as its flexure is of no importance. It could easily be protected from the changes of the tem. perature so troublesome in the tube of a large equatorial. If preferred it might even be exhansted of air, or filled with hydro. gen, and the effect of the changes of temperature thus greatly reduced.

The eyepiece could be mounted on a third pier, and would be so far distant horizontally from the mirror and ohject-glass that there is no reason that it should not be inclosed in a room which may be warmed. The comfort in winter of working in a warm room will be appreciated by those who have used a large telescope in a cold climate. The result is sure to be an increased precision in the observations, and a possibility of prolonging them over longer intervals. A similar effect is produced by the constant direction of the line of sight. No especial observing chair is needed. There is no limit to the size of the attachments which may be made to the eyepiece, since they need not be moved. This is a great advantage in certain spectroscopic and photometric measurements. A strong wind interferes seriously with many observations, as it is impossible to make a telescope so stiff that it will not be shaken by sudden gusts. In the plan here proposed the mirror alone is exposed, and its surface is too small to give trouble.

By means of a long handle the position of the mirror may be regulated from the eyerend, and the declination of the object observed read by small telescopes. If the mirror can be moved at right angles to the meridian $5^{\circ}$ from its central position, an object at the equator may be followed for forty minutes, and other objects for a longer period. Without this motion an object may be followed for three or four minutes by moving the eyepiece alone. Clockwork may be applied to the mirror, or less easily to the eyepiece. The focal length may be increased almost indefinitely if desired, and certain advantages will be thus attained in the diminution in the defects of the object-glass, although those of the reflector will not be affected. If the telescope is to be erected at a great elevation the advantages of the present plan are at once apparent. Many nights of observation would be secured which otherwise would be lost owing to the wind and cold. The simplicity in the construction of the build. ing would be a great advantage, as a large dome in so exposed a situation would be kept free from snow with much difficulty, and might be a source of danger in winter storms. If found impracticable to observe during the winter, it would be possible to have a duplicate mounting below, and remove the lens and mirror from one to the other.

It is evident that the saving of cost would be very great, not only in the observatory building and dome, but in the tube, observing chair, clockwork, \&c.

If a reflector could be constructed whose surface was the portion of a paraboloid whose abscissa equalled that of the focus, the instrument eovld be much simplified. No object-glass would then be required, the reflector taking the place both of mirror and lens. All the light intercepted by the objective would thus 